OPEN ACCESS

Edited by:

Yulei Xie,

Guangdong University of Technology,

China

Reviewed by:

Qinghua Luan,

Hebei University of Engineering, China

Zilong Wang,

Northeast Agricultural University,

China

Zhenxing Zhang,

University of Illinois at Urbana-

Champaign, United States

*Correspondence:

Ping Zhou

chaohupingping@126.com

Specialty section:

This article was submitted to

Hydrosphere,

a section of the journal

Frontiers in Earth Science

Received: 02 August 2021

Accepted: 23 August 2021

Published: 04 October 2021

Citation:

Zhou Y, Zhou P, Zhang Y, Wu C, Jin J,

Cui $Y$ and Ning $S$ (2021)

Characteristics of Precipitation During

Meiyu and Huang-Huai Rainy Seasons

in Anhui Province of China.

Front. Earth Sci. 9:751969.

doi: 10.3389/feart.2021.751969

\section{Characteristics of Precipitation During Meiyu and Huang-Huai Rainy Seasons in Anhui Province of China}

\author{
Yuliang Zhou, Ping Zhou*, Yuliang Zhang, Chengguo Wu, Juliang Jin, Yi Cui and \\ Shaowei Ning
}

College of Civil Engineering, Hefei University of Technology, Hefei, China

Based on the spatial distribution characteristics of the summer monsoon rain belt, Anhui Province of China is divided into three regions, namely, the south of the Yangtze River region (SYA), the Yangtze-Huai region (YHA), and the north of the Huaihe region (NHA). The western Pacific subtropical high (WPSH) ridge and the number of regional rainy days are adopted to identify the onset and ending dates of Meiyu and Huang-Huai rainy seasons during 1957-2020, using China's national standard on "Meiyu monitoring indices." Then precipitation characteristics of these three regions during Meiyu and Huang-Huai rainy seasons are investigated. Finally, the return periods of the precipitation during the northward movement of summer monsoon over Anhui Province are calculated. The results show that there are 7 years without the occurrence of Huang-Huai rainy season, but 8 years with the occurrence of two Meiyu periods and 5 years with two Huang-Huai rainy periods. Thus, there is only one Meiyu period and one Huang-Huai rainy period in the rest 49 years. For the first Meiyu period during 1957-2020, the average onset and ending dates are 14th June and 10th July, respectively, while the corresponding precipitation presents a decreasing tendency from south to north regions in Anhui Province. For the first Huang-Huai rainy period during 1957-2020, the average onset and ending dates are 10th July and 23rd July, respectively, and the corresponding precipitation shows an increasing tendency from south to north regions. For the northward movement of summer monsoon over Anhui Province, the average onset and ending dates are 14th June and 25th July, respectively, and the corresponding precipitation in NHA is close to that in YHA, but less than that in SYA. Annual precipitation in SYA, YHA, and NHA are 999.5, 1010.6, and $618.7 \mathrm{~mm}$, respectively, during the northward movement of summer monsoon over Anhui Province in 2020, and the corresponding return periods are 56.0, 161.6, and 29.2 years, respectively.

Keywords: precipitation characteristics, Meiyu, Huang-Huai rainy season, return period, subtropical high ridge, Anhui Province

\section{INTRODUCTION}

East Asian summer monsoon (EASM) is the most important as well as the specific climate phenomenon over East Asia (Huang et al., 2015; Bombardi et al., 2017; Xu et al., 2021). Summer precipitation in the Eastern Monsoon Region of China (EMRC) is dominated by EASM, resulting in a relatively high occurrence frequency of severe disasters, such as floods and 
droughts (Xia et al., 2017; Yang et al., 2020). Anhui Province is located across both the eastern monsoon region and the northsouth climate transition zone of China. Affected by the weather systems at low and mid-to-high latitudes, the precipitation characteristics in Anhui Province are complicated to identify. Recently, severe droughts and floods have occurred in Anhui Province, especially the consecutive drought over the region of the Yangtze-Huaihe River Basin in 2019, and the floods over the Yangtze River Basin and the Huaihe River Basin in 2020. Therefore, a thorough understanding of precipitation characteristics during the period of the northward movement of summer monsoon over Anhui Province is needed for disasters forecast and prevention.

Previous studies about regional precipitation typically focus on the statistical analysis of the temporal and spatial distribution of extreme precipitation in terms of the trend, abrupt change, and the return period with various time scales for administrative convenience, such as day, month, and season (Wang and $\mathrm{Xu}$, 2002; Ye, 2012; Tang and Chen, 2015; Wang et al., 2015; Ding et al., 2016; Huang et al., 2020). However, there is seldom research focusing on process characteristics of precipitation from the perspective of the large-scale weather systems (Sun and Zhu, 2013; Zhang et al., 2019; Zhang et al., 2020). Precipitation resulted from summer monsoon and typhoons is the two most dominant components of precipitation in flood season in Anhui Province. The variation of summer monsoon precipitation is relatively smaller than that of typhoon precipitation. Thus the summer monsoon precipitation characteristics, including the onset, ending dates, and precipitation amounts during the period of the northward movement of summer monsoon affecting Anhui Province are the scientific and reasonable basis for phase division of scheduling scheme of reservoir, and it also can provide support for the determination of time step for the run theory-based drought process identification with clear physical meaning. Then the issues related to the widely applied monthly precipitation drought index may be solved. The monthly precipitation drought index may not completely reflect precipitation process associated with a large-scale weather system longer than 1 month, which does not begin on the first day nor end on the last day of a month.

Obviously, reservoir operation for flood control and drought relief is strongly subjected to precipitation associated with the large-scale weather systems. The period from the onset of Meiyu season to the end of the Huang-Huai rainy season is the main stage of the summer monsoon main rain belt affecting Anhui Province. The associated precipitation is the most important component of summer precipitation and determines the precipitation characteristics in the flooding season (Water Resources Department of Anhui Province, 1998; Wang et al., 2018) as well as the regional drought and flood pattern. So this study aims, and would be the first, to uncover the characteristics of precipitation during Meiyu and Huang-Huai rainy seasons in Anhui Province based on the synoptic indices, so as to provide data support for the schedule of reservoir operation and flood/ drought disasters prevention.

During Meiyu season, the precipitation in Anhui Province mainly lies in the south of the Yangtze River region in Anhui
Province (SYA) and Yangtze-Huai region in Anhui Province (YHA), while there is little precipitation in the north of Huaihe region in Anhui Province (NHA) (Liang et al., 2007; Ninomiya, 2009). During the Huang-Huai rainy season, the precipitation mainly concentrates in the NHA region, while SYA and YHA are controlled by the northwest Pacific subtropical high (hereinafter, $\mathrm{SH})$ pressure zone with very little precipitation.

Therefore, according to the distribution characteristics of the summer monsoon rain belt, Anhui Province can be divided into three regions, namely, SYA, YHA, and NHA. Zhou et al. (2021) analyzed the characteristics of precipitation during Meiyu season in three regions of Anhui Province. However, they have not studied the precipitation during Huang-Huai rainy season, which may be the most important component of summer precipitation in NHA. In light of this, firstly in this study, Meiyu season and the Huang-Huai rainy season in Anhui Province were identified for the above three regions each year. Following that, the temporal and spatial distribution characteristics of precipitation were analyzed from the perspective of large-scale weather processes. The trend variation and the return period of the precipitation during the period of the northward movement of summer monsoon affecting Anhui Province were also specified. The analysis results can provide scientific support for the planning, design, and operation management of the regional water conservancy project, rational use of regional water resources, and decision making on countermeasure for flood and drought disasters mitigation.

The rest of this article is organized as follows. In the section "Materials and Methods," the methods for identifying the characteristics of Meiyu season and Huang-Huai rainy seasons are presented. In the section "Results and Discussion," the precipitation characteristics of Meiyu and Huang-Huai rainy seasons during 1957-2020 in terms of the duration, onset and ending dates, total amount, and return periods are derived, especially for the year 2020 with severe flood. Conclusion is the last section.

\section{MATERIALS AND METHODS \\ Identification Methods of Meiyu and Huang-Huai Rainy Seasons}

Meiyu is a unique weather and climate phenomenon that occurs over China's Yangtze-Huai River valley, the southern part of the Korean Peninsula, and mid-south regions in Japan from midJune to early-to-mid July (Ge et al., 2008; Wang, 2020). Generally, Meiyu season is determined by the consecutive summer monsoon precipitation resulting from the move of $\mathrm{SH}$, whose ridge surpasses $20^{\circ} \mathrm{N}$ for the first northward jump in mid-June, then stagnates at $20-25^{\circ} \mathrm{N}$ over the above regions (Liang et al., 2007; Zhang, 2007; Ge et al., 2008; Liu and Ding, 2008; Liu et al., 2012; Wang et al., 2018). Following that, in the mid July, the SH ridge surpasses $25^{\circ} \mathrm{N}$ for the second northward jump, then stagnates at $25-30^{\circ} \mathrm{N}$ over the region between the Huang River and the Huai River Basin. Correspondingly, the summer monsoon main rain belt forms the so-called Huang-Huai rainy season. Apart from $\mathrm{SH}$, the central location and the range of the main rain belt of the 
summer monsoon are also affected by other climatic factors, such as the South Asian high, East Asian congestion, and the Indian monsoon (Liang et al., 2007). In previous studies, the proposed thresholds and criteria for identifying Meiyu season and HuangHuai rainy season are typically different from each other until the implementation of the "Meiyu monitoring indices (GB/T 336712017)" from the National Standard of China in 2017 (National Climate Center of the China Meteorological Administration et al., 2017; Zhao et al., 2018).

Based on the "Meiyu monitoring indices (GB/T 33671-2017)" (National Climate Center of the China Meteorological Administration et al., 2017), this study uses the position of the $\mathrm{SH}$ ridge (National Climate Center of the China Meteorological Administration, 2016) and the length of rainy days as the indices to identify the characteristics of Meiyu season and Huang-Huai rainy seasons; that is, the first rainy day when the $\mathrm{SH}$ ridge exceeds $19^{\circ} \mathrm{N}$ for 5 consecutive days is defined as the starting time of Meiyu season. The first day when the $\mathrm{SH}$ ridge exceeds $25^{\circ} \mathrm{N}$ for 5 consecutive days is regarded as the earliest possible ending date of Meiyu season, and the first day when the $\mathrm{SH}$ ridge exceeds $27^{\circ} \mathrm{N}$ for 5 consecutive days is regarded as the latest possible ending date of Meiyu season. If the precipitation in the north of the Huaihe region in Anhui Province suddenly increases or shifts from a non-rainy day to a rainy day while the precipitation in the south of the Yangtze River region of Anhui Province decreases or shifts from a rainy day to a non-rainy day, this day is characterized as the beginning date of Huang-Huai rainy season and the previous day is regarded as the ending date of Meiyu season. When the $\mathrm{SH}$ ridge exceeds $30^{\circ} \mathrm{N}$ for 5 consecutive days, the day before the occurrence of non-rainy days in the north of the Huaihe region is defined as the ending date of Huang-Huai rainy season. If the first 5 days of the $\mathrm{SH}$ ridge exceeding $30^{\circ} \mathrm{N}$ are all non-rainy days, then the last rainy day before the $\mathrm{SH}$ ridge that reaches $30^{\circ} \mathrm{N}$ is regarded as the ending date of Huang-Huai rainy season. If the $\mathrm{SH}$ ridge does not exceed $30^{\circ} \mathrm{N}$ for 5 consecutive days, that is, the $\mathrm{SH}$ ridge does not cross $30^{\circ} \mathrm{N}$ and withdraw southward, the last rainy day before the $\mathrm{SH}$ ridge reaching the northernmost tip is taken as the ending date of Huang-Huai rainy season. Generally, after Huang-Huai rainy season, the $\mathrm{SH}$ ridge jumps north again and North China and Northeast China would enter the rainy season. However, after the end of Huang-Huai rainy season, if the $\mathrm{SH}$ ridge does not immediately jump northward, but first moves southward, such a climatic process leads to the second Meiyu season. After that, the SH ridge jumps northward again or withdraws southward. Under the condition of the jumping northward again, the date that fulfills the conditions for ending the Huang-Huai rainy season is considered as the ending date of the second Huang-Huai rainy season.

\section{Data}

According to "Meiyu monitoring indices (GB/T 33671-2017)" (National Climate Center of the China Meteorological Administration et al., 2017) and "Monitoring Indices of Northwest Pacific Subtropical High (QX/T 304-2015)" (National Climate Center of the China Meteorological Administration, 2016), the processes of Meiyu and HuangHuai rainy seasons are identified mainly according to the atmospheric circulation conditions and meteorological elements. The SH ridge is mainly adopted as an atmospheric circulation element, and the rainy periods, rainy days, and temperature are represented as meteorological elements. The position of the $\mathrm{SH}$ ridge refers to the average position of the ridge of $\mathrm{SH}$ on each meridian within $110-130^{\circ} \mathrm{E}$. Regional rainy days are specified when more than $1 / 3$ of the regional stations have daily precipitation amount more than $0.1 \mathrm{~mm}$ and the average daily precipitation amount of all the stations in the region exceeds $2.0 \mathrm{~mm}$. The upper-air circulation data used to calculate the $\mathrm{SH}$ ridge are the daily average $500 \mathrm{hPa}$ geopotential height and zonal wind speed in the NCEP/NCAR reanalysis data of the United States. The data used to determine the regional rainy days is the daily precipitation of the observation stations in Anhui Province during 1957-2020.

So the required data to identify Meiyu and Huang-Huai rainy processes is obtained as follows: the upper-air circulation data adopts the daily average $500 \mathrm{hPa}$ geopotential height and the zonal wind speed. The data can be freely downloaded from the NCEP/NCAR reanalysis project's webpage: https://psl.noaa.gov/ data/gridded/data.ncep.reanalysis.html. The meteorological data including daily precipitation and average temperature are obtained from 15 observation stations in Anhui Province during 1957-2020, which is provided by the China Meteorological Data Network (http://data.cma.cn). Other related data of precipitation, flood, and drought disasters are collected from the National Hydrological Annual Report provided by Information Center, Ministry of Water Resources, PRC. (http://xxzx.mwr.gov.cn/xxgk/gbjb/sqnb).

\section{RESULTS AND DISCUSSION}

\section{Identification of Meiyu and Huang-Huai Rainy Seasons in Anhui Province}

Provided by the China Meteorological Data Network, Anqing (the station has no data during 2017-2020, which is replaced by Ma'anshan station), Ningguo, and Tunxi stations are the representative stations for the SYA region. The six stations including Chaohu, Hefei, Chuzhou, Lu'an, Huoshan, and Shouxian are representative stations for the YHA region. Five stations in Fuyang, Bengbu, Bozhou, Suzhou, and Dangshan are the representative stations for the NHA region. All of the above stations are shown in Figure 1 (Zhou et al., 2021).

The onset and ending dates of Meiyu and Huang-Huai rainy seasons are identified by the position of the $\mathrm{SH}$ ridge and the rainy days as listed in Supplementary Appendix Table A1 in Appendix.

Supplementary Appendix Table A1 shows the following: 1) During 1957-2020, there are 7 years without the occurrence of Huang-Huai rainy season (only with Meiyu season), which are $1968,1982,1999,2014,2015,2016$, and 2018. At the end of Meiyu season, the SH ridge surpassed $30^{\circ} \mathrm{N}$ directly in $1968,1982,1999$, and 2018. Differently, Meiyu season of 2014 ended on 17th July, and the $\mathrm{SH}$ ridge was located among $27-30^{\circ} \mathrm{N}$ on 18 th and 19 th July (precipitation amount in SYA, YHA, and NHA was 3.5, 0.0, $6.2 \mathrm{~mm}$, respectively). On 20th July, the $\mathrm{SH}$ ridge jumped 


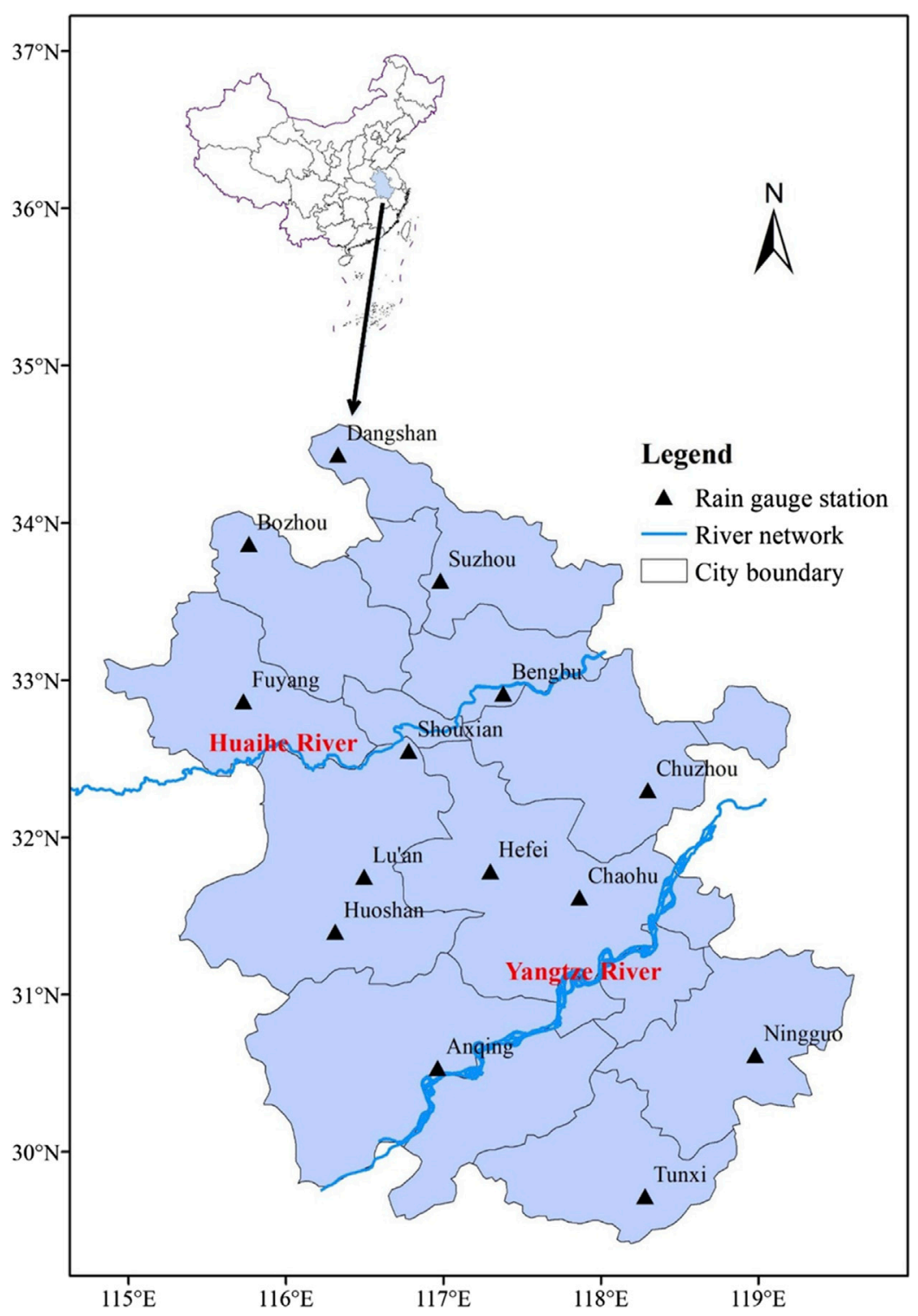

FIGURE 1 | Location of rain gauge stations in Anhui Province.

northward over $30^{\circ} \mathrm{N}$. Meiyu season in 2015 ended on 26th July. Only on 27 th July, the $\mathrm{SH}$ ridge was located at $27-30^{\circ} \mathrm{N}$ (the daily precipitation amount in SYA, YHA, and NHA was 0.0, 0.1, and $6.2 \mathrm{~mm}$, respectively), and the $\mathrm{SH}$ ridge jumped northward over $30^{\circ} \mathrm{N}$ after 27 th July. Meiyu season of 2016 ended on 22 nd July. The $\mathrm{SH}$ ridge was located at $27-30^{\circ} \mathrm{N}$ on $23 \mathrm{rd}$ and 24 th July (there was no precipitation in SYA, YHA, and NHA). After that, the $\mathrm{SH}$ ridge jumped northward over $30^{\circ} \mathrm{N}$. 2) For the 5 years of 1957, 1973, 1977,1998 , and 2009, the SH ridge first laid in the typical range of the $\mathrm{SH}$ ridge during Meiyu season, then moved northward-southward-northward to the typical range of the $\mathrm{SH}$ ridge during Huang-Huai rainy season, Meiyu season, and HuangHuai rainy season, respectively. 3) In 1964, 1985, and 2012, the SH ridge successively laid in the typical range of the $\mathrm{SH}$ ridge during Meiyu season, Huang-Huai season, and Meiyu season. The SH ridge did not stably surpass $30^{\circ} \mathrm{N}$ in 1985 and 2012. In 1964, the SH ridge quickly jumped northward and surpassed $30^{\circ} \mathrm{N}$ after the second Meiyu season. 4) The length of Meiyu and Huang-Huai rainy season exceeded 5 days in most of the recorded years, except for the years of 1964, 1979, 2005, 2009, and 2012. 5) The northward movement of the summer monsoon started in June and ended before the late July in most of the recorded years, except for the following starting time: May 18, 1991; May 27, 2001, and July 9, 1982. In addition, there were 14 years with the summer monsoon ending in August, 10 of them before the start of autumn, while 4 of them in mid-August (they were August 18, 1957; August 14, 1974; August 18, 1998, and August 13, 2020).

To distinguish the rainy periods dominated by the $\mathrm{SH}$ ridge in the same range at different stages, the period when the $\mathrm{SH}$ ridge is first located in the typical range of the $\mathrm{SH}$ ridge during Meiyu 
TABLE 1 | Characteristics of Meiyu and Huang-Huai rainy season during 1957-2020 in Anhui Province.

\begin{tabular}{|c|c|c|c|c|c|c|c|c|}
\hline Stage & $\begin{array}{l}\text { Average } \\
\text { time }\end{array}$ & $\begin{array}{c}\text { Average } \\
\text { duration/d }\end{array}$ & $\begin{array}{c}\text { Shortest } \\
\text { duration/d }\end{array}$ & $\begin{array}{c}\text { Longest } \\
\text { duration/d }\end{array}$ & $\begin{array}{c}\text { Earliest } \\
\text { onset }\end{array}$ & $\begin{array}{l}\text { Latest } \\
\text { onset }\end{array}$ & $\begin{array}{c}\text { Earliest } \\
\text { ending } \\
\text { date }\end{array}$ & $\begin{array}{c}\text { Latest } \\
\text { ending } \\
\text { date }\end{array}$ \\
\hline I & $6.14-7.10$ & 27.0 & $3.0(2012)$ & $56.0(1991)$ & $5.18(1991)$ & 7.09 (1982) & $6.15(1961)$ & $7.31(1987)$ \\
\hline II & $7.10-7.23$ & 14.4 & $3.0(1979,2005)$ & 32.0 (1988) & $6.16(1961)$ & 8.01 (1987) & 7.01 (1964) & $8.14(1974)$ \\
\hline III & & & & & $5.18(1991)$ & 7.09 (1982) & $6.15(1961)$ & $8.13(1957)$ \\
\hline IV & & & & & $6.16(1961)$ & 8.01 (1987) & 7.01 (1964) & $8.18(1957,1998)$ \\
\hline W & $6.14-7.25$ & 42.0 & 19.0 (1982) & $69.0(2011)$ & 5.18 (1991) & 7.09 (1982) & 7.01 (1964) & $8.18(1957,1998)$ \\
\hline
\end{tabular}

Note: The time corresponding to II in the table is the statistical value of 58 years when the Huang-Huai rainy season is not empty; the number before "( )" in the shortest, longest, earliest, and latest column are characteristic values, and the number in " ()" is the year corresponding to the extreme value.

season is specified as the narrowly defined Meiyu season. The period when the $\mathrm{SH}$ ridge is first located in the typical range of the $\mathrm{SH}$ ridge during Huang-Huai rainy season is specified as the narrowly defined Huang-Huai rainy season. The period when the $\mathrm{SH}$ ridge lies in the typical range of the $\mathrm{SH}$ ridge corresponding to Meiyu season is defined as the broadly defined Meiyu season. The period when the $\mathrm{SH}$ ridge lies in the typical range of the $\mathrm{SH}$ ridge corresponding to the Huang-Huai rainy season is defined as the broadly defined Huang-Huai rainy season. The broadly defined Meiyu season includes the narrowly defined Meiyu season, and the broadly defined Huang-Huai rainy season includes the narrowly defined Huang-Huai rainy season. If the $\mathrm{SH}$ ridge does not move southward to the $\mathrm{SH}$ ridge range corresponding to the Meiyu season after the second northward jump, the broadly defined Meiyu season is the same as the narrowly defined Meiyu season. If the $\mathrm{SH}$ ridge does not move southward after the second northward jump, or does not jump northward again after the southward movement to the $\mathrm{SH}$ ridge range corresponding to the Huang-Huai rainy season, the broadly defined Huang-Huai rainy season is the same as the narrowly defined Huang-Huai rainy season. During 1957-2020, there are 8 years with the occurrence of the second Meiyu season, and 5 years among them with the second HuangHuai rainy season. Therefore, there are 8 years in which the broadly defined Meiyu season is different from the narrowly defined Meiyu season, and 5 years in which the broadly defined and narrowly defined Huang-Huai rainy seasons are different. Except for 7 years with only a narrowly defined Meiyu season and 8 years with the second Meiyu season, in the rest 49 years there are one narrowly defined Meiyu season and one Huang-Huai rainy season.

\section{Precipitation Characteristics for Meiyu and Huang-Huai Rainy Seasons}

The timing characteristics of Meiyu and Huang-Huai rainy seasons are shown in Table 1, including the following five stages of summer monsoon in Anhui Province: the narrowly defined Meiyu (stage I), the narrowly defined Huang-Huai rainy season (stage II), the broadly defined Meiyu season (stage III), the broadly defined Huang-Huai rainy season (stage IV), and the whole period of northward movement of summer monsoon (stage $\mathrm{W}$ ).

It can be seen from Table 1 that the average duration of the narrowly defined Meiyu season in 64 years is 27.0 days, and the average duration of the narrowly defined Huang-Huai rainy season in 57 years is 14.2 days. Therefore, the 64 years' average duration of the narrowly defined Huang-Huai rainy season, including the 7-years empty Huang-Huai rainy season, is 12.8 days. Furthermore, it can be seen that the average duration of the period from the onset of Meiyu season to the ending date of the first Huang-Huai rainy season is 39.8 days, which is close to the multiyear average duration of 42.0 days for the northward movement of summer monsoon affecting Anhui Province. In terms of multiyear average, the duration of broadly defined Meiyu season and narrowly defined Meiyu season, as well as broadly defined Huang-Huai rainy season and narrowly defined Huang-Huai rainy season are almost the same. The duration of Meiyu season and Huang-Huai rainy season vary significantly from year to year. The shortest is only 3 days and the longest is 56 days. The shortest duration of Huang-Huai rainy season is 3 days, and the longest is 32 days. The shortest duration of the northward movement of summer monsoon affecting Anhui Province is 19 days, while the longest is 69 days. The earliest onset is 18th May and the latest ending date is 18th August. The characteristics of precipitation at various stages of the northward movement of summer monsoon affecting Anhui Province are shown in Table 2.

It can be seen from Table 2 that in the narrowly defined Meiyu season (i.e., stage I), the 64 years average precipitation amount during this stage decreases from south to north regions in Anhui Province. The precipitation amount in NHA is less than that in SYA or YHA, and the precipitation amount in NHA is only about $1 / 2$ of that in SYA. Specifically, as shown in Supplementary Appendix Table A1, in the 64 years' narrowly defined Meiyu season, there are 46 years in which the precipitation amount in NHA is lower than that in SYA and YHA. In 1976, 1981, 2017, and 2018, the precipitation amount in NHA is lower than that in SYA but slightly higher than that in YHA. In 1962, 1968, 1972, 1982, and 2003, the precipitation amount in NHA is lower than that in YHA but higher than that in SYA (in which, the precipitation amount in NHA during this stage in 1968 and 1972 is close to that in YHA). The precipitation amount in NHA during this stage is higher than that in YHA and SYA in 1958, $1963,1965,1967,1979,2000,2005,2006$, and 2007. Among them, the main rain belt during Meiyu season in 2007 laid in the Huaihe River Basin and, consequently, heavy floods occurred along the Huaihe River; while 1958, 1965, 2000, and 2005 are empty Meiyu years, the precipitation amount in SYA and YHA is very low and less than that in NHA; in 1963 and 1979, the precipitation 
TABLE 2 | Statistical characteristics of precipitation in SYA, YHA, and NHA during 1957-2020 over Meiyu and Huang-Huai rainy seasons.

\begin{tabular}{|c|c|c|c|c|c|c|c|c|c|}
\hline \multirow[t]{2}{*}{ Stage } & \multicolumn{3}{|c|}{ Average value } & \multicolumn{3}{|c|}{ Minimum value } & \multicolumn{3}{|c|}{ Maximum value } \\
\hline & SYA & YHA & NHA & SYA & YHA & NHA & SYA & YHA & NHA \\
\hline I & 346.1 & 239.6 & 169.3 & 10.5 (1958) & 33.3 (1958) & $2.8(2012)$ & 1022.4 (1999) & 955.0 (1991) & 549.5 (2007) \\
\hline II & 30.3 & 55.2 & 109.2 & 0 & 0 & 0 & $200.3(1981)$ & 243.1 (1974) & 478.7 (1965) \\
\hline III & 361.8 & 248.5 & 173.2 & 10.5 (1958) & 33.3 (1958) & $9.3(1988)$ & 1022.4 (1999) & 955.0 (1991) & 549.5 (2007) \\
\hline IV & 31.4 & 67.2 & 112.8 & 0 & 0 & 0 & $200.3(1981)$ & 243.1 (1974) & 478.7 (1965) \\
\hline W & 393.2 & 315.6 & 286.0 & 33.0 (1958) & 72.3 (2001) & 48.3 (2014) & $1022.8(1996)$ & 1010.6 (2020) & $670.2(1965)$ \\
\hline
\end{tabular}

Note: The numbers in "( )" in the table are the year corresponding to the extreme value.

amount in SYA, YHA, and NHA during Meiyu season are very close to each other, and the precipitation amount during Meiyu season in SYA is very close to that in NHA in 1967; in 2006, the main rain belts during Meiyu season laid in SYA, NHA, and the region of south of the Huaihe River (including SYA and YHA) successively, and heavy rainfall occurred when the main rain belt laid in NHA. Supplementary Appendix Table A1 and Table 2 show that the spatial distribution characteristics of precipitation during Meiyu season in Anhui Province are consistent with the national Meiyu regionalization: SYA belongs to the Meiyu region in the middle and lower reaches of the Yangtze River, YHA belongs to the Yangtze-Huai Meiyu region, and the Huaihe River in Anhui Province almost overlaps with the northern boundary of China's Meiyu region (National Climate Center of the China Meteorological Administration et al., 2017).

Table 2 shows that during the narrowly defined Huang-Huai rainy season (stage II), the 64-year average precipitation amount during this stage increases from south to north regions in Anhui Province, and the precipitation amount in NHA is significantly higher than that in SYA and YHA. At this stage, the average precipitation amount in NHA is $109.2 \mathrm{~mm}$, which is about twice of that in YHA and 3.5 times of that in SYA. Specifically, Supplementary Appendix Table A1 shows that there are 7 years with empty Huang-Huai rainy season and 50 years with the precipitation amount in NHA greater than that in SYA and YHA. In 1960, 1971, 1985, and 1986, the precipitation amount in NHA is lower than that in YHA but significantly higher than that in SYA. In 1981, 2006, and 2011, the precipitation amount in NHA is lower than that in SYA. Among these years, the precipitation amount in NHA during Huang-Huai rainy season in 2006 and 2011 is close to that in SYA but less than that in YHA. During Huang-Huai rainy season in 1981, the precipitation in SYA and YHA results from the typhoon; thus, the precipitation amount is significantly higher than that in NHA.

Table 2 shows that the 64-year average precipitation amount from the beginning of the narrowly defined Meiyu season to the end of the narrowly defined Huang-Huai rainy season in SYA, YHA, and NHA is $376.4,294.8$, and $278.5 \mathrm{~mm}$, respectively, and these values are close to 393.2, 315.6, and $286.0 \mathrm{~mm}$ for the 64 -year average precipitation amount during the period of the summer monsoon moving northward in the three regions of Anhui Province. Therefore, the multiyear average precipitation amount in YHA and that in NHA from the narrowly defined Meiyu season to the narrowly defined Huang-Huai rainy season are close to each other but less than that of SYA. In addition, there is little difference in the average precipitation amount between the broadly defined and the narrowly defined Meiyu seasons or the broadly defined and the narrowly defined Huang-Huai rainy seasons. The precipitation amount in the narrowly defined Meiyu season varies from year to year. The minimum precipitation amount during Meiyu season in SYA, YHA, and NHA is less than $50 \mathrm{~mm}$. The maximum precipitation amount during Meiyu season in SYA, YHA, and NHA is greater than $500 \mathrm{~mm}$. Among them, the precipitation amount in SYA and YHA is close to each other, that is, above $1000 \mathrm{~mm}$, while precipitation amount in NHA is only about $1 / 2$ of that in SYA and YHA. The precipitation amount in the narrowly defined Huang-Huai rainy season varies greatly from year to year. Except for the years with empty Huang-Huai rainy season, the minimum precipitation amount at this stage in SYA is only $0.1 \mathrm{~mm}$ and to in NHA is less than $10 \mathrm{~mm}$. The maximum precipitation amount during Huang-Huai rainy season in SYA, YHA, and NHA is also different. The maximum precipitation amount in SYA is less than $150 \mathrm{~mm}$ (except for $200.3 \mathrm{~mm}$ in 1981 under the influence of typhoon), but the maximum value in YHA is close to $250 \mathrm{~mm}$, and the maximum value in NHA is close to $500 \mathrm{~mm}$.

According to the daily precipitation amount series during 1957-2020, the average precipitation amount in SYA, YHA, and NHA from June to July for 64 years is $453.5,341.0$, and $317.8 \mathrm{~mm}$, respectively. Therefore, when summer monsoon moves northward, the average precipitation amount in SYA, YHA, NHA is $393.2,315.6$, and $286.0 \mathrm{~mm}$, respectively, accounting for 87,93 , and $90 \%$ of the precipitation from June to July, respectively. The results show that the precipitation from June to July in Anhui Province is mainly formed by the frontal rain belt resulting from the summer monsoon.

Stage III is different from stage I in 8 years and stage IV is different from stage II in 5 years. The years in which the dates and precipitation of stage III, I, IV, and II are different are shown in Table 3.

Table 3 shows that the second period of Meiyu season begins in July, with the largest average precipitation amount in SYA, successively followed by YHA and NHA, while the 8-year average duration of the period is 10.3 days. All the second periods of Huang-Huai rainy season start after mid July, with the largest average precipitation amount in NHA, successively followed by 
TABLE 3 | Dates and precipitation of the second period of Meiyu and Huang-Huai rainy seasons in SYA, YHA, and NHA during $1957-2020$.

\begin{tabular}{|c|c|c|c|c|c|c|c|c|c|c|}
\hline \multirow[t]{3}{*}{ Year } & \multicolumn{5}{|c|}{ Second period of Meiyu season } & \multicolumn{5}{|c|}{ Second period of Huang-Huai rainy season } \\
\hline & \multirow[t]{2}{*}{ Date } & \multirow[t]{2}{*}{ Duration/d } & \multicolumn{3}{|c|}{ Precipitation/mm } & \multirow[t]{2}{*}{ Date } & \multirow[t]{2}{*}{ Duration/d } & \multicolumn{3}{|c|}{ Precipitation/mm } \\
\hline & & & SYA & YHA & NHA & & & SYA & YHA & NHA \\
\hline 1957 & $7.26-8.13$ & 19 & 216.0 & 155.7 & 40.4 & $8.14-8.18$ & 5 & 0.3 & 24.1 & 24.0 \\
\hline 1973 & $7.19-7.28$ & 10 & 62.9 & 35.8 & 28.8 & $7.29-8.03$ & 6 & 34.7 & 30.9 & 40.6 \\
\hline 1977 & $7.12-7.17$ & 6 & 110.8 & 27.7 & 5.3 & $7.18-7.25$ & 8 & 30.1 & 82.9 & 89.5 \\
\hline 1998 & $7.13-8.02$ & 9 & 206.7 & 121.0 & 96.3 & $8.03-8.18$ & 16 & 18.6 & 90.6 & 182.7 \\
\hline 2009 & $7.24-7.31$ & 21 & 135.5 & 45.6 & 12.3 & 8.01-8.04 & 4 & 16.0 & 8.8 & 2.6 \\
\hline 1964 & $7.18-7.21$ & 4 & 54.6 & 32.7 & 25.0 & & & & & \\
\hline 1985 & $7.18-7.26$ & 8 & 76.2 & 68.8 & 22.2 & & & & & \\
\hline 2012 & $7.09-7.17$ & 9 & 145.4 & 81.7 & 17.2 & & & & & \\
\hline Mean value & & 10.3 & 126.0 & 71.1 & 30.9 & Mean value & 7.8 & 19.9 & 47.5 & 67.9 \\
\hline
\end{tabular}

YHA and SYA, while the 5-year average duration of the period is 7.8 days.

\section{Return Period of Precipitation During Meiyu and Huang-Huai Rainy Seasons}

According to the precipitation amount during Meiyu and HuangHuai rainy seasons in SYA, YHA, and NHA in Supplementary Appendix Table A1, the frequency analysis of the precipitation amount corresponding to the northward movement of summer monsoon affecting Anhui Province in these three regions is analyzed. In 1996, 1999, and 2020, the precipitation amount during Meiyu and Huang-Huai rainy seasons in SYA is 1022.8, 1022.4, and $999.5 \mathrm{~mm}$, respectively. The historical floods in China, since 1840 (Luo, 2006), and the precipitation during the extreme Meiyu events years (e.g., 1954) in the YangtzeHuai Meiyu region are used for comparison and analysis (Water Resources Department of Anhui Province., 1998; Wang and $\mathrm{Xu}, 2002$; Luo, 2006; Zhang, 2007; Ding et al., 2016; Information Center of the Ministry of Water Resources, 1983-2020). The precipitation during Meiyu and Huang-Huai rainy seasons of these 3 years are higher than the corresponding precipitation in the years with severe flood occurred in the Yangtze River Basin, such as in 1896 and 1931, but slightly lower than that of 1954 with the largest flood in history in the basin (according to the daily precipitation records in the Tunxi Station, the precipitation amount in this period is $1185.0 \mathrm{~mm}$, which is the largest ever recorded). Therefore, the precipitation amount during this period of the above 3 years can be considered as the second, third, and fourth largest values since 1840 .

The precipitation amount during Meiyu and Huang-Huai rainy seasons in YHA in 1991 and 2020 is 959.8 and $1010.6 \mathrm{~mm}$, respectively. These two values are higher than that during this period in the years with severe flood occurred in the Huaihe River Basin, such as in 1921, 1931, and 1954 (Luo, 2006). Among which, according to the daily precipitation records of the representative stations in YHA (Chuzhou, Huoshan, and Hefei stations), the precipitation amount during this period of 1954 is $849.2 \mathrm{~mm}$, which is far less than the abovementioned 2 years. Therefore, the precipitation amount of these 2 years during this period can be considered as the first and second extreme values since 1840 .
The precipitation during Meiyu and Huang-Huai rainy seasons from 1957 to 2020 in NHA is a continuous time series without extraordinary value. According to the records (Information Center of the Ministry of Water Resources, 1983; Luo, 2006), the precipitation amount during this period in 1954 reaches the maximum value since 1840 . According to the daily precipitation series of the representative stations in NHA (Suzhou, Bozhou, and Fuyang stations), the precipitation during this period of 1954 is $819.2 \mathrm{~mm}$. Consequently, the return period of the precipitation during this period in 1954 is about 181 years.

The P-III curve is used to fit the frequency of precipitation during Meiyu and Huang-Huai rainy seasons in SYA, YHA, and NHA, respectively. The fitting results are shown in Figure 2.

It can be seen from Figure 2 that the P-III curve can well fit the empirical frequency points. The mean value, coefficient of variation, and coefficient of skew of the precipitation during Meiyu and Huang-Huai rainy seasons in SYA are $381.3 \mathrm{~mm}, 0.59$, and 1.28, respectively. The three coefficients of the P-III curve in YHA are $295.5 \mathrm{~mm}, 0.63$, and 1.65 , respectively. The three coefficients of the P-III curve in NHA are $286.0 \mathrm{~mm}, 0.53$, and 1.14 respectively. Based on these parameters of the frequency curve, it can be obtained that the precipitation amount during this period with the return period of 180 years in SYA is $1201.9 \mathrm{~mm}$. It is slightly higher than the maximum value of $1185.0 \mathrm{~mm}$ at the Tunxi station over 181 years since 1840 . The precipitation amount during this period with the return period of 180 years in NHA is $821.9 \mathrm{~mm}$, which is also very close to the maximum value of $819.2 \mathrm{~mm}$ in this region over 181 years since 1840 . It demonstrates that the P-III curve is suitable to be taken as the frequency curve of precipitation during this period in Anhui Province. Precipitation under different return periods in SYA, YHA, and NHA are given in Table 4.

According to P-III curve and their parameter values, the return periods of $63.9,63.8$, and 56.0 years are specified for the precipitation of 1022.8, 1022.4, and $999.5 \mathrm{~mm}$ during Meiyu and Huang-Huai rainy seasons in SYA in 1996, 1999, and 2020, respectively. The return periods corresponding to the precipitation of 959.8 and $1010.6 \mathrm{~mm}$ in the year of 1991 and 2020 in YHA are 118.6 and 161.6 years, respectively. The return periods for the precipitation of $670.2,612.9$, and $618.7 \mathrm{~mm}$ in 


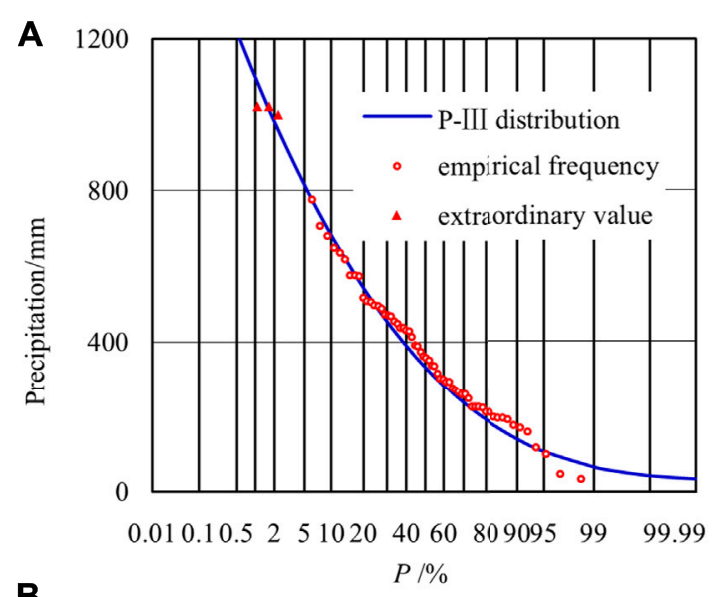

B

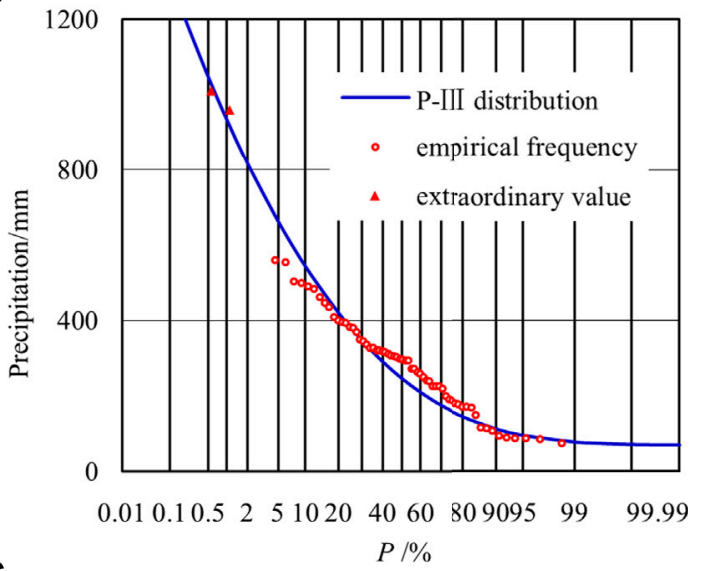

C

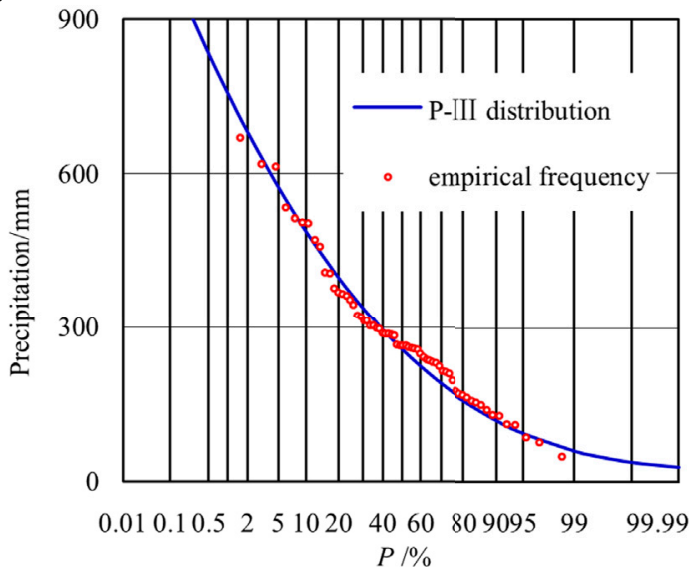

FIGURE 2 | Frequency curve of precipitation during Meiyu and HuangHuai rainy seasons from 1957 to 2020 in (A) SYA, (B) YHA, and (C) NHA.

TABLE 4 | Precipitation during Meiyu and Huang-Huai rainy seasons in SYA, YHA, and NHA for some typical return periods (unit: $\mathrm{mm}$ ).

\begin{tabular}{lcccccccc}
$\begin{array}{l}\text { Return } \\
\text { period/a }\end{array}$ & $\mathbf{1 0 0}$ & $\mathbf{5 0}$ & $\mathbf{3 0}$ & $\mathbf{2 0}$ & $\mathbf{1 0}$ & $\mathbf{5}$ & $\mathbf{3}$ & $\mathbf{2}$ \\
\hline SYA & 1100.9 & 979.4 & 888.0 & 813.6 & 682.6 & 543.7 & 432.9 & 334.6 \\
YHA & 931.5 & 816.3 & 730.6 & 661.7 & 542.4 & 419.8 & 325.9 & 246.9 \\
NHA & 757.9 & 680.5 & 622.0 & 574.2 & 489.4 & 398.3 & 324.5 & 257.9
\end{tabular}

NHA in the year of 1965, 2007, and 2020 are 45.7, 27.8, and 29.2 years, respectively.

\section{CONCLUSION}

Based on the position of the $\mathrm{SH}$ ridge and the regional rainy days as the indices, Meiyu and Huang-Huai rainy seasons during 1957-2020 are identified. The precipitation characteristics of Meiyu and Huang-Huai rainy seasons in SYA, YHA, and NHA are analyzed, respectively. The return period of precipitation in the above three regions are specified when the summer monsoon moves northward over Anhui Province. The main conclusions are given as follows:

1) The 64-year average precipitation amount during Meiyu season in Anhui Province decreases from south to north regions. The 64-year average precipitation amount of the first period of Meiyu season in SYA, YHA, and NHA is $346.1,239.6$, and $169.3 \mathrm{~mm}$, respectively. The 64-year average precipitation amount during Huang-Huai rainy season in Anhui Province increases from south to north regions. The three regional precipitations in the first period of Huang-Huai rainy season are 30.3, 55.2, and $109.2 \mathrm{~mm}$, respectively.

2) With the northward movement of summer monsoon over Anhui Province, the 64-year average precipitation in YHA and NHA is close to each other, but less than that in SYA. The average precipitation amount in these three regions is 393.2, 315.6 , and $286.0 \mathrm{~mm}$, respectively, and it varies from year to year. The precipitation amount in SYA, YHA, and NHA during this period accounts for 87,93 , and $90 \%$ of the precipitation amount during June-July, respectively, implying that the precipitation during June-July is formed by the frontal rain belt resulting from the northward movement of summer monsoon.

3) The average duration of the first period of Meiyu season is 27.0 days from 14th June to 10th July. The first Huang-Huai rainy season mainly starts from 10th July to 23rd July with duration of 14.4 days. The northward movement of summer monsoon over Anhui Province mainly starts from 14th June to 25th July with duration of 42.0 days. The onset and ending dates of Meiyu season, Huang-Huai rainy season, and the northward movement of summer monsoon over Anhui Province vary greatly from year to year. Particularly, there are 8 years with the occurrence of a second period of Meiyu season, and 5 years with a second HuangHuai rainy season out of 64 years.

4) The return periods corresponding to the precipitation of $1022.8 \mathrm{~mm}$ at $1996,1022.4 \mathrm{~mm}$ at 1999 , and $999.5 \mathrm{~mm}$ at 2020 in SYA are 63.9, 63.8, and 56.0 years, respectively, which are lower than the return period of the precipitation in 1954. The return periods of the precipitation of $959.8 \mathrm{~mm}$ at 1991 and $1010.6 \mathrm{~mm}$ at 2020 in YHA are 118.6 and 161.6 years, respectively. It is higher than the return period of precipitation during this period in 1954. The return periods corresponding to the precipitation of $670.2 \mathrm{~mm}$ at $1965,612.9 \mathrm{~mm}$ at 2007 , and $618.7 \mathrm{~mm}$ at 2020 in NHA are 45.7, 27.8, and 29.2 years, respectively. It is also lower than the return period of precipitation during this period in 1954. 


\section{DATA AVAILABILITY STATEMENT}

Publicly available datasets were analyzed in this study. This data can be found here: http://data.cma.cn, https://psl.noaa.gov/data/ gridded/data.ncep.reanalysis.html.

\section{AUTHOR CONTRIBUTIONS}

$\mathrm{YZ}$ and JJ designed the research. PZ, YZ, CW, YC, and SN performed the research. $\mathrm{YZ}$ and $\mathrm{YZ}$ wrote the manuscript. All the authors contributed to the article and approved the submitted version.

\section{REFERENCES}

Bombardi, R. J., Pegion, K. V., Kinter, J. L., Cash, B. A., and Adams, J. M. (2017). Sub-seasonal Predictability of the Onset and Demise of the Rainy Season over Monsoonal Regions. Front. Earth Sci. 5, 14. doi:10.3389/ feart.2017.00014

Ding, J. L., Wang, H., Dong, Z. R., and Wang, F. W. (2016). Characteristics of Extreme Precipitation in Anhui from 1960 to 2013. J. Arid Meteorol. 34 (2), 252-260. doi:10.11755/j.issn.1006-7639(2016)-02-0252

Ge, Q., Guo, X., Zheng, J., and Hao, Z. (2008). Meiyu in the Middle and Lower Reaches of the Yangtze River since 1736. Chin. Sci. Bull. 53 (1), 107-114. doi:10.1007/s11434-007-0440-5

Huang, D.-Q., Zhu, J., Zhang, Y.-C., Huang, Y., and Kuang, X.-Y. (2015). Assessment of Summer Monsoon Precipitation Derived from Five Reanalysis Datasets over East Asia. Q.J.R. Meteorol. Soc. 142 (694), 108-119. doi:10.1002/qj.2634

Huang, J. P., Zhang, G. L., Yu, H. P., Wang, S. S., Guan, X. D., and Ren, Y. (2020). Characteristics of Climate Change in the Yellow River basin during Recent 40 Years. J. Hydraul. Eng. 51 (9), 1048-1058. doi:10.13243/ j.cnki.slxb.20200603

Information Center of the Ministry of Water Resources (1983). National Hydrological Annual Report. Beijing: China Water \& Power Press.

Lee, S.-E., and Seo, K.-H. (2013). The Development of a Statistical Forecast Model for Changma. Weather Forecast. 28 (6), 1304-1321. doi:10.1175/WAF-D-1300003.1

Liang, P., Tang, X., Ke, X. X., and He, J. H. (2007). Review of Study on Influencing Factors of China Meiyu. J. Meteorol. Sci. 27 (4), 464-471. doi:10.3969/ j.issn.1009-0827.2007.04.018

Liu, D., He, J., Yao, Y., and Qi, L. (2012). Characteristics and Evolution of Atmospheric Circulation Patterns during Meiyu over the Jianghuai valley. Asia-pacific J. Atmos. Sci. 48 (2), 145-152. doi:10.1007/s13143012-0014-6

Liu, Y., and Ding, Y. (2008). Teleconnection between the Indian Summer Monsoon Onset and the Meiyu over the Yangtze River Valley. Sci. China Ser. D-earth Sci. 51 (7), 1021-1035. doi:10.1007/s11430-008-0073-9

Luo, C. Z. (2006). A Compilation of Survey Data on the Historical Floods in China. Beijing: China Bookstore press.

National Climate Center of the China Meteorological Administration (2017). Climate Center of Shanghai, Climate Center of Wuhan, Climate Center of Anhui, Climate Center of Jiangsu, Meteorological Bureau of Yangzhou. Meiyu Monitoring Indices (GB/T 33671-2017). Beijing: China Standard Press.

National Climate Center of the China Meteorological Administration (2016). Monitoring Indices of Northwest Pacific Subtropical High (QX/T 304-2015). Beijing: China Meteorological Press.

Ninomiya, K. (2009). Characteristics of Precipitation in the Meiyu-Baiu Season in the CMIP3 20th Century Climate Simulations Kozo NINOMIYA. J. Meteorol. Soc. Jpn. 87 (4), 829-843. doi:10.2151/jssj.87.82910.2151/jmsj.87.829

Sun, Y., and Zhu, W. J. (2013). Rainstorm Characteristics during Meiyu Period in Jiangsu and its Effect on Water Levels of Lower Reaches of the Changiiang

\section{FUNDING}

This work was supported by the National Key Research and Development Project of China (Grant No. 2017YFC1502403) and the National Natural Science Foundation of China (Grant Nos 51779067 and 51709071).

\section{SUPPLEMENTARY MATERIAL}

The Supplementary Material for this article can be found online at: https://www.frontiersin.org/articles/10.3389/feart.2021.751969/ full\#supplementary-material

River. Sci. Geogr. Sin. 33 (2), 238-243. doi:10.13249/ j.cnki.sgs.2013.02.23810.5846/stxb201206120844

Tang, Y. H., and Chen, X. H. (2015). Multi-scale Spatio-Temporal Characteristics and Influence of Precipitation Variation in Zhujiang River basin during the Last 50 Years. Sci. Geogr. Sin. 35 (4), 476-482. doi:10.1007/ s11589-011-0776-4

Wang, J. (2020). Relationships between Jianghuai Meiyu Anomaly and the Collaborative Evolution of Wave Trains in the Upper and Lower Troposphere in Mid-july of 2020. Front. Earth Sci. 8, 597930. doi:10.3389/ feart.2020.597930

Wang, J., Zhou, Y. L., Zhou, P., and Jin, J. L. (2018). Study on the Spatial Characteristics of Plum rains in Anhui Province Based on Set Pair Analysis. Water Resour. Power 36 (11), 1-4.

Wang, S. C., Cheng, X. F., and Yang, W. W. (2015). Characteristics of Rainfall in Chaohu basin in the Last 56 Years and Their Influences on Droughts and Floods. Res. Soil Water Conserv 22 (3), 289-294. doi:10.13869/ j.cnki.rswc.2015.03.052

Wang, X. R., and Xu, M. (2002). Some Statistical Characteristics of Summer Precipitation in Anhui Province. J. Anhui Normal Univ. (Nat Sci. Ed. 25 (3), 281-285. doi:10.14182/j.cnki.1001-2443.2002.03.020

Water Resources Department of Anhui Province (1998). Flood and Drought Disasters in Anhui. Beijing: China Water \& Power Press.

Xia, J., Duan, Q.-Y., Luo, Y., Xie, Z.-H., Liu, Z.-Y., and Mo, X.-G. (2017). Climate Change and Water Resources: Case Study of Eastern Monsoon Region of China. Adv. Clim. Change Res. 8 (2), 63-67. doi:10.1016/j.accre.2017.03.007

Xu, B., Chen, H., Gao, C., Zeng, G., and Huang, Q. (2021). Abnormal Change in spring Snowmelt over Eurasia and its Linkage to the East Asian Summer Monsoon: the Hydrological Effect of Snow Cover. Front. Earth Sci. 8, 594656. doi:10.3389/feart.2020.594656

Yang, W., Yang, H., and Yang, D. (2020). Classifying Floods by Quantifying Driver Contributions in the Eastern Monsoon Region of China. J. Hydrol. 585, 124767 doi:10.1016/j.jhydrol.2020.124767

Ye, Z. W. (2012). Precipitation Change in Flood Season and its Relationship with EASM in the Hongze lake Catchments in Recent 60 Years. Sci. Geogr. Sin. 32 (11), 1358-1363. doi:10.13249/j.cnki.sgs.2012.011.135810.1556/oh.2012.34m

Zhang, J., Zhou, X., Jiang, S., Tu, L., and Liu, X. (2020). Monsoon Precipitation, Economy and Wars in Ancient China. Front. Earth Sci. 8, 317. doi:10.3389/ feart.2020.00317

Zhang, Y. (2007). Extremely Heavy Meiyu over the Yangtze and Huaihe Valleies in 1931. Adv. Water Sci. 18 (1), 8-16. doi:10.14042/ j.cnki.32.1309.2007.01.002

Zhang, Y., Li, T. J., Li, J. Y., and Zhong, D. Y. (2019). Influence of the Westerlies and the South Asia Monsoon on Water Vapor Transport and Precipitation in the Three-River Headwaters Region during the Rainy Season. Adv. Water Sci. 30 (3), 348-358. doi:10.14042/j.cnki.32.1309.2019.03.005

Zhao, J. H., Chen, L. J., and Xiong, K. G. (2018). Climate Characteristics and Influential Systems of Meiyu to the South of the Yangtze River Based on the New Monitoring Rules. Acta Meteorol. Sin. 76 (5), 680-698. doi:10.11676/ qxxb2018.025

Zhou, Y., Zuo, Y., Zhang, Y., Jin, J., Zhou, P., Wu, C., et al. (2021). Identification and Characteristics Analysis of Meiyu in Anhui Province 
Based on the National Standard of Meiyu Monitoring Indices. Hydrol. Res. doi: $10.2166 /$ nh. 2021.042

Conflict of Interest: The authors declare that the research was conducted in the absence of any commercial or financial relationships that could be construed as a potential conflict of interest.

Publisher's Note: All claims expressed in this article are solely those of the authors and do not necessarily represent those of their affiliated organizations, or those of the publisher, the editors, and the reviewers. Any product that may be evaluated in this article, or claim that may be made by its manufacturer, is not guaranteed or endorsed by the publisher.

Copyright $\odot 2021$ Zhou, Zhou, Zhang, Wu, Jin, Cui and Ning. This is an open-access article distributed under the terms of the Creative Commons Attribution License (CC $B Y)$. The use, distribution or reproduction in other forums is permitted, provided the original author(s) and the copyright owner(s) are credited and that the original publication in this journal is cited, in accordance with accepted academic practice. No use, distribution or reproduction is permitted which does not comply with these terms. 